\title{
Culturally Relevant Resources List ${ }^{1}$
}

Lisa Guion, Samantha Chattaraj, Stephanie Sullivan Lytle, Gae Broadwater, and H. Wallace Goddard ${ }^{2}$

\section{Developing Programs to Effectively Work with Multi-need, Diverse Audiences (Diversity Project)}

A culturally relevant resource list is a critical link in connecting Children, Youth and Families at Risk (CYFAR) Extension professionals and paraprofessionals (educators) with culturally relevant resources to educate diverse audiences in various subject areas. This is why CYFAR educators from across the nation requested such a list be developed when filling out the CYFERnet environmental scan and needs assessment surveys. The Diversity Project Team designed the following resource list in response to the needs expressed by CYFAR educators by searching extensively to identify some examples of culturally relevant resources that support and strengthen CYFAR programming. The resources were reviewed by team members, county faculty and/or state specialists. All resources came from credible sources in an attempt to further ensure the accuracy of subject content.

This culturally relevant resource list is in no way a comprehensive listing, but a small sample of materials currently available. It is, however, a great starting point for CYFAR Extension educators to refer to for the purpose of connecting with diverse, multi-need audiences in more relevant and meaningful ways. The list provides educational resources for teaching specific subject matter through culturally and ethnically diverse curricula, lessons, games, and activities. In listing these specific resources, our hope is that CYFAR educators continue to seek out resources with cultural relevance on their minds, and consequently, in the heart of their lessons.

Some educators may contend that a curriculum does not need to be customized to different ethnic groups. For example, some may feel that the principles that guide good parenting are the same for all humans, so a specific curriculum targeting a certain ethnic group is unwarranted. Others might adamantly object and feel that this position advocates a "one size fits all" approach. The Diversity Project Team acknowledges the fact that most basic principles that are addressed in Extension subject areas apply to all individuals, such as what constitutes proper nutrition, good money management practices, and so forth. However, the way the principles are presented and taught in the curriculum may need to vary to more effectively reach diverse audiences due to different cultural norms, values, beliefs, practices, and traditions within a given ethnic group. Therefore, before choosing any curriculum or educational resource for a specific group, an educator should ask:

1. This document is PE069, one of a series of the Department of Family, Youth and Community Sciences, Florida Cooperative Extension Service, University of Florida, UF/IFAS, Gainesville, FL 32611: First published: September 2003. Reviewed by Millie Ferrer, Ph.D., interim associate dean for Extension, Department of Family, Youth and Community Sciences; Carolyn Perkins, MPH, health specialist, Prairie View A\&M University, Cooperative Extension Program; Robin Roper, NC State University Cooperative Extension Service, and 13 other CYFAR Extension Professionals. Please visit the EDIS Web site at http://edis.ifas.ufl.edu

2. Lisa Guion, Ed.D., project director \& principal investigator; Samantha Chattaraj, project coordinator; Stephanie Sullivan Lytle, project coordinator; al of the department of Family, Youth and Community Sciences, Florida Cooperative Extension Service, University of Florida, UF/IFAS, Gainesville, FL 32611, Gae Broadwater, specialist, Kentucky State University; H. Wallace Goddard, Ph.D., CFLE, University of Arkansas Cooperative Extension Service.

The Institute of Food and Agricultural Sciences is an equal opportunity/affirmative action employer authorized to provide research, educational information and other services only to individuals and institutions that function without regard to race, color, sex, age, handicap or national origin. For information on obtaining other extension publications, contact your county Cooperative Extension Service office. Florida Cooperative Extension Service/Institute of Food and Agricultural Sciences/University of Florida/Christine Taylor Waddill, Dean. 
- Is the content accurate and researchbased?

- Is the material written at a reading level appropriate for the audience?

- Are the applications and activities appropriate for their needs?

- Does the curriculum cover issues/topics on the subjects that are important to the audience?

- Does it provide application exercises for applying the ideas that would be interesting to the audience?

- Are the examples relevant to the audiences' experiences?

- Does the content reflect the norms, values and preferences of the target audience?

- When related to the subject content, are the cultural observances acknowledged and/or celebrated?

- Does the curriculum involve users as partners in applying the principles taught in the lessons to their lives?
The most effective way to get answers to these questions (determine if a resource is culturally relevant) is to involve the target audience in selecting which research-based materials they prefer. An advisory committee could serve in this capacity if it was made up of diverse individuals who represented all segments of the target audience. A focus group with key members of the target audience is also another strategy. While it may be difficult to find a curriculum that pleases everyone, it is feasible that a curriculum can be identified that will be accepted by, and therefore more effective with, most of your target audience. The following resource list is only the beginning of a deeper quest for culturally relevant curriculum and materials. 


\section{A Sample of}

Culturally Relevant Resources List

Developing Programs to Effectively Work with Multi-need, Diverse Audiences

\section{Family and Community Resources}

1. Title: All My Money

Author: Karen Chan

Publisher: University of Illinois Extension Consumer and Family Economics

Date of Publication: 2001

Order Information: Visit: https://webstore.aces.uiuc.edu/shopsite/ACE-3ab.html

OR Call: 1-800-345-6087

Cost: $\$ 100$

Subject Area: Money Management

Target Audience: Limited Resource Audiences (adults)

Description: All My Money is an extensive curriculum to help educators teach limited-resource audiences key skills in money management. The curriculum is easy to understand and has many handson activities that make it a realistic and useful tool in the field of money management. The areas covered by All My Money are envelope budgeting, understanding credit, handling credit problems, managing a checking account and more. The vastly informative curriculum contains a 40-page trainer's manual, lesson-planning guides, handout masters and budgeting cards, as well as other teaching materials. Finally, the materials are also available in Spanish as a supplement kit called Todo Mi Dinero.

2. Title: Getting on Financial Track

Author: Celvia S. Dixon

Publisher: The University of Tennessee Agricultural Extension Service

Date of Publication: 1998

Order Information: Available online in PDF at http://www.utextension.utk.edu/publications/financial/default.asp

For more information contact Etta Mae Westbrook, University of Tennessee, PO Box 1071, Knoxville, TN 37901-1071 Phone: (423) 974-8198

Cost: Free of charge

Subject Area: Money management- Bankruptcy

Target Audience: Limited Resource Audiences (adults)

Description: Getting on Financial Track addresses the financial problems of the low-income audiences. The curriculum features reproducible lesson plans, transparencies and slides on bankruptcy training for limited resource audiences. The curriculum offers a number of activities and exercises to prepare the participants to deal with the complexities of filing bankruptcy and to get life back on track after filing bankruptcy. In addition, since bankruptcy is a sensitive topic for the participants to discuss, the curriculum offers a wide choice of ice-breaking and introductory exercises as well. Through the thought-provoking activities, the curriculum aids the participants in developing a spending plan by cataloging the different kinds of expenditures. The curriculum is available in Portable Document Format and can be downloaded free of charge.

3. Title: Gathering of Native Americans

Author: Multiple

Publisher: Center for Substance Abuse Prevention

Date of Publication: 2001

Order Information: Visit: http://p2001.health.org/CTI05/Cti05ttl.htm

Cost: Free of Charge 
Subject Area: Substance Abuse Education

Target Audience: Native American community (adults)

Description: Gathering of Native Americans (GONA) was developed by the Center for Substance Abuse Prevention (CSAP) as a part of the Community Partnership Training (CCPT) Project to lend a hand to Community Partnership grantees in making efforts to lessen and prevent alcohol and other drug abuse. A team of Native American substance abuse prevention trainers and curriculum developers was assembled to work on the development of the GONA training curriculum to ensure that the GONA curriculum was developed by and for Native Americans. The GONA training is based upon the four levels of human growth and responsibility which are found in Native culture: Belonging - A place for all ages and a place for all kinds of people; Mastery - Empowerment of all; Interdependence - Community leadership; and Generosity - Teachers/elders give their knowledge and teachings to the future generations. The training is divided into four modules and each module comes with innovative, interactive and reproducible handouts, transparencies and resources. The goal of the curriculum is to present a substance abuse prevention strategy framework that is based on the intrinsic principles of traditional Native cultures.

4. Title: Helping Youth Succeed: Bi-Cultural Parenting for South East Asian Families

Authors: D. Detzner, B. Ziong and P. Eliason,

Publisher: University of Minnesota Extension Service

Date of Publication: 1999

Order Information: Visit:

http://www.extension.umn.edu/distribution/familydevelopment/DE7240.html

Cost: $\$ 295$

Subject Area: Parenting, Community development

Target Audience: South East Asian parents

Description: The curriculum Helping Youth Succeed is an outcome of the combined efforts of the authors to develop a culturally sensitive parenting resource for South East Asian parents of bi-cultural preadolescents and adolescent youth. The authors recognized the fact that South East Asians face many language, cultural, legal, and social barriers while rearing their children. Thus, the authors focused on designing a curriculum that would deliver a culturally relevant parenting guide to the South East Asian community in the United States. This curriculum features a facilitator's guide, a videotape, a guide to the video and a booklet called 'family stories'. The 68 page facilitator's guide gives background information on the South East Asian community, and suggestions on planning lessons based on the content of the video tape. The tape features six family stories about the common problems that South East Asian parents face while raising their children in the United States. Each family story is presented from the perspective of both American mainstream and South East Asian values. There are also possible solutions to the "problems" that are discussed on the video. The guide to the video and the 100 page booklet "family stories" can be used to gain better insight to the family stories shown on the video. The curriculum is available in four South East Asian languages (Cambodian, Hmong, Laotian and Vietnamese) and English.

5. Title: Job Readiness Tool Kit

Author: Alejandra Domenzain

Publisher: National Council of La Raza

Date of Publication: 1999

Order Information: Call 202-785-1670

Cost: $\$ 15$

Subject Area: Career Development

Target Audience: Latino/Hispanic teens and adults

Description: Job Readiness Tool Kit aims at developing a resource to facilitate job-readiness among Latino and Hispanic youth and adults. This curriculum seeks to present a broad topic such as jobpreparation in a culturally relevant fashion by referring to some of the culture-specific problems/barriers many Latinos/Hispanics face at work or while applying for a job. The author makes a special note of the 
fact that in his effort to draw a relationship between the cultural norms of the Latino/Hispanic culture and the problems that Latinos/Hispanics face professionally, he has taken great steps to avoid stereotyping Latinos/Hispanics. Rather, most of the Latinos/Hispanics would be able to relate to the case studies and characters used in the different examples throughout the curriculum. To address a wide range of issues this well-organized curriculum is divided into seven parts:

- Getting Started and Motivated

- Self-Assessment and Promotion

- Job Search and Selection

- Applying for the Job

- Getting Ahead in the Workplace

- Problem-Solving At Work

- Career Planning.

The lessons direct educators through culturally- appropriate, interactive activities for job training workshops. The lessons are extremely interactive owing to the abundance of activities, worksheets, discussions, research, interviews with peers or mentors, role-plays, group projects, presentations, selfassessment exercises, and games. The curriculum is available in both English and Spanish.

6. Title: Sabemos y Podemos- Learning for Social Action

Author: Rachel Martin, Ph.D. with Alejandra Domenzian

Publisher: Western Union and National Council of La Raza

Date of Publication: 1999

Order Information: Call 202-785-1670.

Cost: $\$ 15$

Subject Area: Youth and Adult Education, Literacy, Social Action, Community Involvement

Target Audience: Hispanic/Latino youth \& adults

Description: Sabemos y Podemos- Learning for Social Action was developed by Western Union in association with National Council of La Raza, as a part of their Aprender Es Poder education program. This curriculum is an excellent starting point for promoting literacy, English as Second Language and adult basic education among Latino and Hispanic individuals. Sabemos y Podemos seeks to use language as a power (poder) for bringing about social changes in the Hispanic/Latino community. The curriculum addresses wide-ranging issues concerning the Hispanic/Latino community. Therefore, the curriculum is divided into three broad sections: 'Educating our Children,' 'Our Working Lives,' and 'Community Action.' The three sections cover issues that include maintaining family history and culture, bilingual-education, language rights of children, myths involving the Hispanic/Latino immigrants, contribution of the immigrant laborers to the American society, and improving the career prospects of the Hispanic/Latino adults. The curriculum is replete with reproducible exercises, guidelines, role-plays, examples and illustrations that educators can use to impart knowledge about issues of concern to the Hispanic/Latino community. Sabemos y Podemos- Learning for Social Action is available in both English and Spanish.

7. Title: Your Money \& Your Life

Author: Karen Chan

Publisher: University of Illinois Extension Consumer and Family Economics

Date of Publication: 2002

Order Information: Visit: https://webstore.aces.uiuc.edu/shopsite/ACE-4-CD.html

Cost: $\$ 30$

Subject Area: Money Management, Workforce Preparation

Target Audience: Limited Resource Audiences (adults)

Description: Your Money \& Your Life is a follow up resource to All My Money. It is a "train-the trainer" resource that comes in Microsoft Word documents on a Compact Disc. The resource is designed to assist educators in meeting the requirements of limited resource audiences who are just entering the workforce or trying to make their job situation better. There are eight lessons in the curriculum that help 
the participants learn the importance of broad financial concepts such as insurance, job benefits, and savings. The topics covered by the curriculum are: Managing debt, avoiding money traps, using financial institutions, choosing insurance, learning about job benefits, making money with money, taking advantage of public benefits and understanding taxes.

\section{Children and Youth Resources}

8. Title: Exploring Native American and Puritan Cultures

Author: Multiple

Publisher: Artsedge

Date of Publication: 1999

Order Information: Visit:

center.org/teaching materials/curricula/curricula.cfm?subject id=SOC

Cost: Free of Charge

Subject Area: Cultural traditions, arts and crafts, study skills

Target Audience: Grades 9 through 12

Description: Exploring Native American and Puritan culture is divided into three lessons: "Learning about Archetypal Journey," "Jonathan Edwards and Theology" and "Native American Poetry and Sand Paintings." The first and the third lessons are most relevant for Native American students as these two lessons are designed to train the students about Native American visual arts, performing arts, language arts and social studies. The first lesson, "Learning about Archetypal Journey," focuses on the classic Native American art of story telling. As a part of the lesson plan it is recommended to show the movie The Natural to aid the students in familiarizing with the idea of symbolism (The movie is available at Blockbuster). Later, the students read and scrutinize a short story that uses Native American structure of writing stories. Students also write a creative short story that follows the Native American story telling form. The third lesson, "Native American Poetry and Sand Paintings" encourages students to study Native American poetry and art by learning about Native American culture, traditions and legends. The activities in the lesson persuade the students to construct a sand painting that shows the relationship between a deity, nature and the individual. The objective is to help the students understand how early Native Americans observed the relationship between God, nature and individuals. The strategies adopted by the lesson like silent reading, note taking, group discussion and hands on activities improve the students' artistic and social skills and raise their cultural awareness and sensitivity.

9. Title: Harlem

Author: Joyce Gill-Thompson

Publisher: Artsedge

Date of Publication: 2000

Order Information: Visit:

center.org/teaching_materials/curricula/curriculum.cfm?curriculum_id=475\&mode=full

Cost: Free of Charge

Subject Area: Arts/Music, Cultural Traditions, Social Studies

Target Audience: Grades 3 through 6

Description: Harlem is a vast resource about African American culture and heritage. This curriculum has six parts:

- Harlem Renaissance: A Living Museum

- Creative Voices of Harlem

- Musical Harlem

- Portrait of a Place, Portrait of a Family

- Street Games

- The Great Migration

The first lesson, Harlem Renaissance: A Living Museum is based upon the theme of the book Harlem by Walter Dean Myers. Through the book students explore the lives and times of celebrated AfricanAmericans of the Harlem Renaissance period. As an activity, students write brief monologues to play 
the role of the eminent people from the Harlem era to create a living museum. In Creative Voices of Harlem, students learn about some of the most important artists from the Harlem. The students analyze a poem by Langston Hughes, and then they explore an artist of their choice from the Harlem Renaissance, and share information about the artist with the class. In Musical Harlem, the objective is to help the students recognize musical styles and musicians belonging to Harlem. The focus of the lesson is to show how music united the Harlem community. Audio samples are available as a part of the lesson. Students examine the basic features of jazz and its musicians, take part in a group dance activity, and share in language arts and visual arts exhibition. In the fourth lesson- Portrait of a Place, Portrait of a Family, the focal point is the practice of oral histories and written chronicles. This lesson provides an opportunity to the students to respond to the lives and stories of the people of Harlem. In Street Games, information is shared about the street games of Harlem such as stickball, kick the can, and tag as well as hand games, chant-and-response activities, and rope skipping. Finally, in the last lesson The Great Migration, students learn about the history of immigration of African Americans to Harlem, beginning with the original relocation of Africans to North America.

10. Title: Invent: An African American Inventor's Curriculum

Author: Multiple

Publisher: Ohio State University Extension

Date of Publication: 1999

Order Information: Visit: http://www.ag.ohio-state.edu/ cyfarsol/invent.html

Cost: Free of Charge

Subject Area: Multidisciplinary including Science, Music, Communication, Agriculture, Public Safety, History

Target Audience: Grades 4 through 8

Description: Invent is a curriculum that can be used by Extension educators to teach their students about the contributions by African Americans in various fields. This well-organized and easy-to-use curriculum has distinctive lesson plans that consist of unit background information, experimental activities, suggested evaluation techniques, careers, reading references and "digging deeper" exercises. Invent is based upon the concise character sketches and achievements of great African American luminaries like George Washington Carver, B.B. King, J.H. Dickinson, Granville Woods, Dr. Earnest Just, Benjamin Banneker, Madame Walker and Harriet Tubman. Invent seeks to bring about ingenuity and invention among the youth by providing them with experimental activities, scope for creativity, critical thinking, problem-solving and motivation. However, the best part of this curriculum is that through the narration of the accomplishments of African Americans in various fields, Invent skillfully unfolds the history, tradition and principles of the rich African American culture.

11. Title: Multicultural Art Activities

Author: Betty Gaglio Cavanaugh

Publisher: Teacher Created Materials, Inc

Date of Publication: 1994

Order Information: www.teachercreated.com

Cost: $\$ 11.99$

Subject Area: Multi-disciplinary, including reading, writing, arts and crafts, history and more

Target Audience: Elementary school children, grades 1 through 3

Description: Multicultural Art Activities encourages a hands-on exploration of many ethnic groups through the creation of art. The activities are designed to involve cutting, pasting, drawing, tracing, coloring, painting, and crafts of all shape and size. The art activities highlight a variety of cultures including African art, Native American art, Asian art, Hispanic art, Ancient Civilizations art, and a mixture of art from other cultures as well. The arts and crafts differ in difficulty level from activity to activity, but all are designed at a high interest level for elementary school children.

\section{Title: Multicultural Holidays}

Author: Julia Jasmine 
Publisher: Teacher Created Materials, Inc.

Date of Publication: 1994

Order Information: www.teachercreated.com

Cost: $\$ 24.99$

Subject Area: Multi-disciplinary, including reading, writing, arts and crafts, history, songs and dance

Target Audience: Elementary school children

Description: Understanding what people are celebrating and why is helpful in becoming more culturally competent, which can lead to stronger connections with people from diverse cultures and backgrounds. The recognition of cultural diversity through the celebration of holidays is particularly appropriate in school environments since more holidays are observed in school than anywhere else. All of the holidays in Multicultural Holidays can be taught (or celebrated) in a variety of ways. Some of them are more serious than others and lend themselves to research projects, reports, or even puzzles, while others seem to demand parades and parties. Using a holiday to bridge the gap between one culture and another benefits everyone and teaches cultural diversity in a positive and uplifting way.

13. Title: Native American Arts and Cultures

Author: Mary E. Connors

Publisher: Teacher Created Materials, Inc.

Date of Publication: 1994

Order Information: www.teachercreated.com

Cost: $\$ 15.99$

Subject Area: Multi-disciplinary, including reading, writing, arts and crafts, history, dance and drama Target Audience: Elementary school children, grades 1 through 3

Description: The legacy of the rich Native American cultures has contributed greatly to the uniqueness of contemporary American culture. Native American Arts and Cultures explores various aspects of Native American life through traditional arts and crafts. Some of the areas highlighted include: homes and lodges, quest for food, animals in life and legend, dance and drama, basketry and pottery, transportation and trade, clothing and jewelry, and toys and games. Although all the activities are based on tradition, they often employ non-traditional materials due to the targeted elementary school audience. The quest of Native Americans has always been to live in harmony with the world, and that is the theme of this hands-on arts and crafts resource.

14. Title: Tracing the Path: African American contributions to Chemistry in the Life Sciences

Author: Faculty of the Department of Academic Programs

Publisher: American Chemical Society

Date of Publication: 1994

Order Information: Contact ACS, Education Division, 1155 16th Street NW, Washington, DC 20036

Phone No: 202-872-4075 \& 800-227-5558

Cost: $\$ 20$

Subject Area: Science and Technology

Target Audience: Grades 5 through 12

Description: This curriculum comes in a set that includes an 18-minute long video, and a 12-page long teacher's guide. The curriculum seeks to introduce young African Americans and their families to the contributions made by the African Americans in the field of chemistry. The video endeavors to trace the outstanding accomplishments, in chemistry, of the pre-colonial Africans in Africa, African Americans during the late 1800s and early to mid-1900s in the United States, and modern African Americans. The teacher's guide is a supplement to the video. It features lesson plans in the form of discussion topics and hands-on activities. The curriculum has made an earnest effort to encourage young African Americans to study science.

15. Title: Understanding Native American Culture Through Environmental Education Author: Department of Teaching and Learning Technologies at the University of Nevada, Reno 
Publisher: The University of Nevada, Reno

Date of Publication: 1998

Order Information: Visit: http://www.unr.edu/nnap/nnc_intro.htm

Cost: Free of charge

Subject Area: Environmental science

Target Audience: Elementary school children, grade four

Description: Project Willow is a hands-on science curriculum for elementary school children. This curriculum was designed to introduce fourth graders to basic environmental science concepts from the perspective of the Washoe Indians. It traces Washoe encounters with the local environment in both traditional and modern times. The curriculum moves through the three seasons of ancient Washoe life, pausing at points along the way to explore the Washoe culture and provide students with a general picture of traditional Washoe life. The unit concludes by examining the effect of Euro-American settlement on Washoe lands. The connection of the Washoe culture with the natural environment is explored, along with how the loss of traditional lands has had a profound effect on the Washoe as a people.

\section{Health Resources}

16. Title: Cultural Food Pyramids/Complementary Nutrition Archives

Author: Southeastern Michigan Dietetic Association

Publisher: SEMDA-Southeastern Michigan Dietetic Association

Date of Publication: NA

Order Information: Visit: http://www.semda.org/info/

Cost: Free of charge

Subject Area: Food and nutrition

Target Audience: Adults of various ethnic groups such as African Americans, Hispanics and Latinos

Description: The Cultural Food Pyramids were created by SEMDA members and dietetic students collaboratively. This website provides food pyramids and recipes for a variety of diverse audiences across many ethnic and cultural groups. Facts are also included on various herbs and supplements. In addition to these individually tailored food pyramid guides, another resource for a diversity of recipes is Delicious Heart-Healthy Latino Recipes by the National Institutes of Health. A final resource for diverse recipes is Heart-Healthy Home Cooking, African Style also by the National Institutes of Health. These recipes are published by the U.S. Department of Health and Human Services and can be found in the November 1996 and September 1997 issues respectively.

17. Title: ETHNOMED - Diabetes Education Materials

Author: Carey Jackson, MD; Tao Kwan-Gett, MD; Ellen Howard et al.

Publisher: University of Washington's Health Science Library and the Harborview Medical Center's Community House Calls Program.

Date of Publication: 2003

Order Information: Available online at www.ethnomed.org

Cost: Free of charge

Subject Area: Health

Target Audience: Adults of various ethnic groups such as African Americans, Asians \& Latinos. Description: EthnoMed is a web site that provides comprehensive medical and cultural information about different ethnic groups. Although the web site focuses on providing information about specific immigrants and refugee groups in the Seattle area, much of the cultural and health information can be applied to other geographical areas also. The objective of Ethno Med is to bridge the cultural and language barriers during medical treatments to people from diverse ethnic backgrounds. Thus, the "Diabetes Education Materials" were created. Educators can download patient education materials on diabetes free of charge from www.ethnomed.org (look at the bottom of the home page). The diabetes education materials are available in PDF format in seven different languages: English, Cambodian, Vietnamese, Oromo, Somali, Tigrean and Spanish. The materials consist of sample class flyers to 
promote the training, interactive handouts and audio tapes in different languages, and valuable information about diet, exercises, and testing for diabetes. The information in the education materials is culture specific as the information takes into account the cultural norms and food habits while developing diet charts for diabetes patients.

18. Title: The Food Pyramid

Author: The Nutrition Education for New Americans Project/Dept. of Anthropology and Geography

Publisher: Georgia State University, Atlanta, Georgia

Date of Publication: NA

Order Information: Call 404- 651-2542 or visit: http://multiculturalhealth.org/

Cost: Varies. For detail please visit: http://multiculturalhealth.org/index/Purchase Materials

Subject Area: Nutrition

Target Audience: Adults of diverse ethnic groups such as African American, Asian, Hispanic, \& more. Description: The Food Guide Pyramid is a general guide that lets readers choose a healthy diet that is right for them. The Pyramid calls for eating a variety of foods to get the nutrients needed and eating the right amount of calories to maintain a healthy weight. The food pyramid comes in thirty languages and crosses many cultures and ethnic groups within the United States. Each specific food pyramid gives examples of food that is common to that ethnic group for each section of the pyramid.

19. Title: Take Care of Yourself! Lessons To Raise Diabetes Awareness in Latinos Author: University of California Cooperative Extension Department of Nutrition Publisher: University of California Agriculture and Natural Resources

Date of Publication: 2003

Order Information: Call 1-800-994-8849, or (510) 642-2431, or e-mail: danrcs@ucdavis.edu

Cost: $\$ 12$

Subject Area: Nutrition

Target Audience: Adult Latinos who are at-risk for diabetes

Description: Take Care of Yourself! is part of a curriculum for nutrition educators working in the Expanded Food and Nutrition Education Program (EFNEP). These lessons on diabetes awareness and prevention are about motivating the participants to make dietary changes and to lower some of their barriers to change. Other lessons discuss building skill needed to make these changes. The background information on diabetes gives educators a good understanding for teaching and prepares them for possible problems and questions that might come up in their own class discussions. Recommendations for the type of information to discuss with class participants are given in the sample lesson plans. The curriculum also includes a glossary of terms and a bibliography of sources on diabetes and related topics.

20. Title: Your Journey to Better Health

Author: Multiple

Publisher: USDA

Date of Publication: Revised version: 2002

Order Information: Order \#EX47-99 from the National Food Service Management Institute, University of Mississippi, Attn: Sales Department, PO Drawer 188, University, MS 38677-0188 1-800321-3054 or fax 800-321-3061

Cost: $\$ 5.75$

Subject Area: Food and Nutrition, Health

Target Audience: Native American adults

Description: Your Journey to Better Health was developed by the USDA for Native American individuals and families. The curriculum addresses the issues relating to poor health and unhealthy diet among Native Americans by drawing a link between diet and health by including chapters that explored information on nutrition, food safety, physical activities, meal planning and recipe search. The practical, straightforward writing style makes the curriculum a useful resource for promoting healthy lifestyle among the Native Americans. Educators can extrapolate the information and activities 
provided in Your Journey to Better Health to supplement any other curricula or programs they may be using in the field of food, nutrition and health for the Native Americans.

This resource is provided by Developing Programs to Effectively Work With Multi-need, Diverse Audiences

\section{Project Team:}

Lisa Guion, Ed.D., Project Director \& Principal Investigator, University of Florida Samantha Chattaraj, Project Coordinator, University of Florida

Stephanie Sullivan Lytle, Project Coordinator, University of Florida

Gae Broadwater, Kentucky State University

H. Wallace Goddard, PhD., University of Arkansas

Carolyn Perkins, Prairie View A\&M University, Texas

Robin Roper, North Carolina University 